\title{
Protein SORLA
}

\section{Übergewicht durch insulinempfindliche Fettzellen}

Im Gehirn markiert das Protein SORLA Alzheimer-Proteine, in Fettzellen den Insulinrezeptor für das Recycling. Als Teil der zellulären Sortiermaschinerie wirkt es so gegen die Alzheimer-Plaques, Fettgewebe jedoch macht es empfindlich gegenüber Insulin. Die Fettzellen lagern dadurch übermäßig Fett ein.

Das Forschungsteam um Prof. Thomas Willnow und Postdoktorandin Dr. Vanessa Schmidt vom Max-DelbrückCentrum für Molekulare Medizin in der Helmholtz-Gemeinschaft (MDC) sowie Forschenden des Deutschen Instituts für Ernährungsforschung, der Universität Leipzig und der Universität Umeå in Schweden stellte seine Ergebnisse nun in der Fachzeitschrift Journal of Clinical Investigation vor.

\section{Wirkmechanismus von SORLA nachgewiesen}

Den Forschenden gelang der detaillierte Nachweis des Wirkmechanismus von SORLA an menschlichen Proben, Mäu- sen und Zellkulturen. Ein statistischer Zusammenhang zwischen dem Gen für SORLA und Fettleibigkeit war zuvor nur aus genetischen Studien bekannt. Die Analyse von Proben von 362 übergewichtigen Personen zeigte: Je mehr SORLAProteine im Fett vorliegen, desto ausgeprägter ist auch das Übergewicht. Den kausalen Zusammenhang zwischen Protein und Übergewicht belegten Versuche an Mäusen. Gefüttert mit kalorienreicher Kost, wurden Tiere mit überaktivem SORLA-Gen im Fettgewebe zügig fettleibig. Tiere mit inaktiviertem SORLA-Gen, die die gleiche Kost erhielten, waren dagegen magerer als Mäuse mit gewöhnlichem SORLA-Spiegel.

Die Ursache: Zellen mit einem Übermaß an SORLA sprachen stärker auf Insulin an. In Zellkulturen verfolgten die Forschenden den Weg von SORLA und Insulinrezeptoren durch die Zelle. SORLA markierte die Insulinrezeptoren für die Wiederverwendung und blockierte deren Abbau. Der erhöhte SORLA-Spiegel führte zu mehr Insulinrezeptoren auf der Zelloberfläche. Dadurch wurden die Zellen überempfindlich für das Hormon und blockierten den Fettabbau zu stark.

Eine Störung des Insulinstoffwechsels ist vor allem von der Diabetes-Erkrankung bekannt. Mit den nun vorliegenden Ergebnissen stellen Schmidt und Willnow einen ganz neuen Signalweg des Stoffwechselhormons vor, der auch klinische Relevanz hat. „Nicht nur Insulinresistenz wie bei Diabetes Typ 2 ist ein Problem“, bemerkt Willnow dazu. „Auch, wenn das Fettgewebe übersensitiv gegenüber Insulin ist, kommt es zur Stoffwechselstörung." Die Mäuse mit zu viel SORLA nahmen allerdings erst extrem zu, als sie sich von fett- und kohlenhydratreichem „Fast Food“ ernährten. „Erst wenn man sich ungesund ernährt, wird es ein Problem, wenn das Fettgewebe zu empfindlich auf Insulin reagiert,“ sagt Willnow.

Pressemeldung Max-Delbrück-Centrum für Molekulare Medizin in der HelmholtzGemeinschaft, 20.6.2016 